Crohn's disease

\title{
Increased gut permeability in Crohn's disease: is TNF the link?
}

\section{P R Gibson}

\section{Evidence now implicates tumour necrosis factor $\alpha$ in global impairment of intestinal barrier function, and may be the link between the leaky gut and Crohn's disease}

l: testinal epithelial barrier function and Crohn's disease are intimately related. An impaired barrier in association with active inflammation leads to increased exposure of the mucosal innate and acquired immune system to proinflammatory molecules. This has been implicated as a major driving force for mucosal inflammation. In active disease, macromolecules can permeate the barrier at an increased rate via, for example, breaks in the integrity of the epithelium (ulceration, erosions, or nests of apoptotic cells) ${ }^{1}$ via increased pinocytotic uptake of luminal proteins, ${ }^{23}$ and via increased proportion of M cells in the terminal ileum. ${ }^{4}$ Impaired barrier function may precede the clinical development of the disease and might represent a marker of increased susceptibility to Crohn's disease. This notion derives from observations made in several centres using different techniques that paracellular permeability is abnormal in $10-20 \%$ of first degree relatives of patients with Crohn's disease. ${ }^{5-10}$ That this reflects exposure to an environmental factor is supported by the observations from three studies that increased intestinal permeability is also found in $13-36 \%$ of spouses of patients with Crohn's disease. ${ }^{8911}$

Tumour necrosis factor $\alpha$ (TNF- $\alpha)$ and Crohn's disease are intimately related. Mucosal levels and inflammatory cell production of TNF- $\alpha$ are elevated. Therapy with monoclonal antibodies to TNF- $\alpha$, such as infliximab, leads to a rapid reduction in inflammation and healing in many patients, and remission can be maintained with ongoing therapy. ${ }^{12-14}$ The spectacular effect of infliximab has been attributed not only to its ability to mop up TNF- $\alpha$ but also to induction of apoptosis in activated $\mathrm{T}$ cells. ${ }^{15}$

TNF- $\alpha$ and intestinal epithelial barrier function are also intimately related. TNF- $\alpha$ increases paracellular permeability via an effect on the tight junctions. ${ }^{16}$ While it is theoretically possible that TNF- $\alpha$ may also increase paracellular permeability by induction of epithelial apoptosis, evidence is scant. TNF- $\alpha$ suppressed the expression and activity of the intestinal p-glycoprotein MDR-1 in an intestinal epithelial cell line, ${ }^{17}$ an effect that would impair the efflux of xenobiotics taken up by epithelial cells. ${ }^{18}$ It also may play a role in facilitating bacterial translocation across the epithelium, as recently demonstrated in glutamine starved Caco-2 cells. ${ }^{19}$ In this issue of Gut, Söderholm and colleagues ${ }^{20}$ extend the role of TNF- $\alpha$ by demonstration that expression of mRNA for TNF- $\alpha$ in mucosa correlates with endosomal uptake of horseradish peroxidase (HRP) in resected ileal mucosa mounted in Ussing chambers (see page 1813). A causal relationship was suggested by experiments with T84 cell monolayers where relatively low concentrations of TNF- $\alpha$ increased uptake of HRP. In other words, evidence now implicates TNF- $\alpha$ in global impairment of intestinal barrier function, including leakier tight junctions, increased uptake of proteins from the lumen, and less efficient efflux of foreign substances from the cells, all favouring increased permeation of luminal macromolecules to the lamina propria.

All of these associations raise the key issue of whether TNF- $\alpha$ is the link between the leaky gut and Crohn's disease. Intestinal permeability in patients with active Crohn's disease normalises following successful antiTNF (infliximab) therapy. ${ }^{21}$ However, this observation may simply reflect healing of the injured mucosa independently of the mechanism by which it was achieved, and does not resolve this issue. The real answers may be found in understanding the mechanisms responsible for the reduced barrier that occurs across the intact epithelium, such as that observed in first degree relatives and spouses of patients with Crohn's disease.

It is first necessary to consider the more general issue of what aspects of barrier function clinical measures of intestinal permeability are actually assessing. Permeability probes used all measure predominantly the efficiency of the paracellular route. ${ }^{22}$ There are no readily applicable clinical measures of transcellular permeability. Yet the luminal proinflammatory molecules and bacteria, which induce mucosal inflammation, are likely to traverse the physically intact epithelium via the transcellular rather than paracellular route. Despite the likelihood that these routes of uptake are independently controlled, relatives of patients with Crohn's disease who have elevated paracellular permeability exhibit evidence of excessive antigen exposure, suggesting that more than just paracellular pathways are leaky. ${ }^{23}$ In other words, it appears that measures of paracellular permeability in this setting are reflecting general barrier dysfunction not just that between cells, and that a common mechanism needs to be invoked. The findings of Söderholm et al that histologically normal mucosa, albeit in patients with severe Crohn's lesions nearby, exhibited elevated endosomal uptake of the marker protein the marker prtoeinin association with an increase in TNF- $\alpha$ mRNA and presumably epithelial exposure to TNF- $\alpha^{20}$ might suggest TNF- $\alpha$ as a candidate. A similar situation of increased intestinal epithelial exposure to TNF- $\alpha$ might also occur in first degree relatives with elevated paracellular permeability as evidence for subclinical inflammation of the bowel in this population has been reported. ${ }^{24}$ It is feasible that interactions between the lumen and epithelium in association with, for example, microbial dysbiosis or changes in the soluble component of luminal contents, might lead to induction of TNF- $\alpha$ production and secretion by subepithelial lamina propria cells, with a subsequent diffuse increase in exposure of TNF- $\alpha$ to intestinal epithelium, but without clear histological abnormalities.

Another issue that arises is how the epithelial effects of TNF- $\alpha$ fit into the mode of action of infliximab in inducing remission, in healing the mucosal lesions, and in maintaining remission. That TNF- $\alpha$ is a cytokine of major pathogenic significance in Crohn's disease is incontrovertible, as shown by the powerful and rapid healing response to infliximab and maintenance of remission in many patients with moderately severe disease. It has been generally believed that the remission inducing effect of infliximab is the result of taming activated $\mathrm{T}$ cells, possibly via induction of their destruction by apoptosis. ${ }^{15}$ In active Crohn's disease, it is likely that epithelium distant from the major inflammatory lesion is being 
exposed to increased amounts of TNF- $\alpha$ and that therapy with anti-TNF- $\alpha$ regimens will minimise that exposure and correct potential abnormalities of permeability. Reducing a widespread leaky gut might have a greater effect on well being than we currently appreciate. The mechanisms by which anti-TNF- $\alpha$ regimens maintain remission may also involve epithelial effects rather than or in addition to direct effects on immune and inflammatory mechanisms.

Thus recent studies indicate a potentially more expansive role for TNF- $\alpha$ in intestinal homeostasis, barrier function, and pathogenesis of intestinal inflammation in Crohn's disease. Caution however must be exercised in the interpretation of many of the recent observations, particularly as they are very dependent on results from experimental studies in cell line models of epithelium or from observations in tissue from patients with advanced disease. It will be of key importance to assign an in vivo relevance to many of these findings before speculation can be converted to real understanding. Nevertheless, it is an appealing unifying concept that TNF- $\alpha$ is a major mechanism underlying global barrier dysfunction in Crohn's disease, both early and late in its pathogenesis.

Gut 2004;53:1724-1725.

doi: 10.1136/gut.2004.047092

Correspondence to: Professor P R Gibson, Department of Gastroenterology and Monash University Department of Medicine, Box Hill Hospital, Box Hill, Victoria 3128, Australia; Peter.Gibson@med.monash.edu.au

\section{REFERENCES}

1 Bojarski C, Bendfeldt K, Gitter AH, et al. Apoptosis and intestinal barrier function. Ann NY Acad Sci 2000:915:270-4.

2 Malin M, Isolauri E, Pikkarainen P, et al. Enhanced absorption of macromolecules. A secondary factor in Crohn's disease. Dig Dis Sci 1996:41:1423-8.

3 Söderholm JD, Peterson, KH, Olaison G, et al. Epithelial permeability to protein in the noninflamed ileum of Crohn's disease. Gastroenterology 1999;117:65-72.

4 Cuvelier CA, Quatacker J, Mielants H, et al. M cells are damaged and increased in number in inflamed human ileal mucosa. Eur J Morphol 1993;31:87-91.

5 Hollander D, Vadheim CM, Brettholz E, et al. Increased intestinal permeability in patients with Crohn's disease and their relatives. A possible etiological factor. Ann Intern Med 1986;105:883-5.

6 Katz KD, Hollander D, Vadheim CM, et al. Intestinal permeability in patients with Crohn's disease and their healthy relatives. Gastroenterology 1989:97:927-31.

7 May GR, Sutherland LR, Meddings JB. Is small intestinal permeability really increased in relations of patients with Crohn's disease? Gastroenterology 1993;104:1627-32.

8 Peeters M, Geypens B, Claus D, et al. Clustering of increased small intestinal permeability in family with Crohn's disease. Gastroenterology 1997; 113:802-7.

9 Soderholm JD, Olaison G, Lindberg E, et al. Different intestinal permeability patterns in relatives and spouses of patients with Crohn's disease: an inherited defect in mucosal defence? Gut 1999;44:96-100.

10 Secondulfo $M$, de Magistris L, Fiandra R, et al. Intestinal permeability in Crohn's disease patients and their first degree relatives. Dig Liver Dis 2001;33:680-5

11 Breslin NP, Nash C, Hilsden RJ, et al. Intestinal permeability is increased in a proportion of spouses of patients with Crohn's disease. Am J Gastroenterol 2001;96:2934-8.

12 Baert FJ, D'Haens GR, Peeters $M$, et al. Tumor necrosis factor alspha antibody (infliximab) therapy profoundly down-regulated the inflammation in Crohn's ileocolitis. Gastroenterology 1999;116:22-8.
13 D'Haens G, Van Deventer S, Van Hogezand R, et al. Endoscopic and histological healing with infliximab anti-tumor necrosis factor antibodies in Crohn's disease: a European multicenter trial. Gastroenterology 1999:116:1029-34.

14 Hanauer SB, Fegan BG, Lichtenstein GR, et al. Maintenance infliximab for Crohn's disease: the ACCENT I randomised trial. Lancet 2002:359:1541-9.

15 Di Sabatino A, Ciccocioppo R, Cinque B, et al. Defective mucosal $T$ cell death is sustainably reverted by infliximab in a caspase dependent pathway in Crohn's disease. Gut 2004;53:70-1.

16 Bruewer M, Luegering A, Kucharzik T, et al. Proinflammatory cytokines disrupt epithelial barrier function by apoptosis independent mechanisms. J Immunol 2003;171:6164-72.

17 Belliard AM, Lacour B, Farinotti R, et al. Effect of tumor necrosis factor-alpha and interferongamma on intestinal P-glycoprotein expression, activity, and localization in Caco-2 cells. J Pharm Sci 2004;93:1524-36.

18 Ho G-T, Moodie FM, Satsangi J. Multidrug resistance 1 gene (P-glycoprotein 170): an important determinant in gastrointestinal disease? Gut 2003:52:759-66.

19 Clark EC, Patel SD, Chadwick PR, et al. Glutamine deprivation facilitates tumour necrosis factor induced bacterial translocation in Caco-2 cells by depletion of enterocyte fuel substrate. Gut 2003:52:224-30.

20 Söderholm JD, Streutker C, Yang P-C, et al. Increased epithelial uptake of protein antigens in the ileum of Crohn's disease mediated by tumour necrosis factor $\alpha$. Gut 2004;53:1813-6.

21 Suenart $\mathbf{P}$, Bulteel V, Lemmens L, et al. Anti-tumor necrosis factor treatment restored the gut barrier in Crohn's disease. Am J Gastroenterol 2002;97:2000-4.

22 Meddings JB, Gibson PR, Tagkalidis P. Mucosal defenses and intestinal permeability. In: Satsangi J, Sutherland LR, eds. Inflammatory Bowel Diseases. Edinburgh: Churchill Livingstone, 2003:63-83.

23 Thidleifsson B, Sigthorsson G, Criglia N, et al. Subclinical intestinal inflammation: an inherited abnormality in Crohn's disease relatives? Gastroenterology 2003;124:1728-37.

24 Yacyshyn BR, Meddings JB. CD45RO expression on circulating CD19+ B cells in Crohn's disease correlates with intestinal permeability. Gastroenterology 1995; 108:132-7. such beneficial effect is testament to the ingenuity of the pioneer endoscopists and their partners in industry. EBS is now an everyday event in endoscopy units around the world, the great majority being completed safely and achieving the desired goal. Indeed, we tend to take EBS for granted. The recent National Institutes of Health Consensus Conference Panel deemed endoscopic retrograde cholangiopancreatography (ERCP) and EBS to be essential tools in the management of patients with acute cholangitis, pancreatitis, and choledocholithiasis. ${ }^{3}$ EBS has been shown to be safe and effective in experienced hands but it is undoubtedly associated with both short and long term complications. ${ }^{4}$

Recurrent bile duct stone formation is not uncommon following EBS. The literature suggests an incidence ranging from $4 \%$ to $24 \% .{ }^{5}{ }^{6}$ Further ERCP with extension of the previous sphincterotomy is often the treatment of choice in patients with recurrent innovative work was performed in the face of considerable antagonism from the surgical community, which considered that endoscopists had regarded as surgical "turf". In the 30 years since, countless thousands of patients have benefited from EBS, being spared major surgical and radiological procedures. That an electrosurgical incision of a centimetre or less can have 
choledocholithiasis but little is know of the long term results and complications of this treatment. In this issue of Gut, Sugiyama and colleagues ${ }^{7}$ attempt to address these questions (see page 1856). In a retrospective review of ERCP cases seen between 1977 and 1998, the authors identified 84 patients who required repeat ERCP (with or without EBS) for recurrent bile duct stones. Over a mean follow up period of 11.7 years, 31 of 84 patients (37\%) developed complications, including choledocholithiasis, cholangitis, and cholecystitis. The rate of recurrent stone formation was $31 \%$. Twenty one of 26 patients $(81 \%)$ with recurrent choledocholithiasis and four patients with acute cholangitis required repeat EBS. Three of these patients $(10 \%)$ went on to develop a further recurrence of biliary stones, two being treated by further EBS. Using univariate and multivariate analysis, the authors found that "late" biliary complications of EBS were associated with the following risk factors: interval between initial EBS and second EBS $<5$ years, bile duct diameter $>15 \mathrm{~mm}$, and the presence of a periampullary diverticulum. They concluded that multiple ERCPs (even three or more) were safe and effective. They advocated careful follow up for patients with identifiable risk factors.

The authors' data are interesting but are their findings in agreement with the existing literature on EBS? The rate of late complications of EBS in this series was $31 \%$, significantly higher than previously reported. Indeed, the same group of authors previously reported a long term complication rate of $9.7 \%$ in a study that included 100 patients followed for a mean of 14.2 years. ${ }^{8}$ In a separate study, with a mean follow up of 15 years, late complications were seen in $24 \%$ of EBS patients. ${ }^{4}$ A possible explanation for this discrepancy is selection bias: inclusion of patients requiring a second ERCP may have biased the study in favour of biliary pathology. There may also have been unrecognised patient factors that predisposed some individuals to be "stone formers". At the time of repeat ERCP, the authors noted the presence of a "non-enlarged biliary orifice" in 49 of 84 patients $(58 \%)$. We believe that it is wrong to equate this appearance with papillary stenosis. A small sphincterotomy site may still be sufficient to allow bile to drain unimpeded into the duodenum. However, if we accept that these EBS sites were indeed stenotic, then we must ask why this complication was so common. Were the initial sphincterotomies too small? It is difficult to assess this, as 31 of the patients described had their EBS performed at other institutions. The technical ability and expertise of the endoscopists involved is unknown, further confounding the results. Many years ago, Dr Steven Silvis (Minneapolis) demonstrated in dogs that following EBS, the size of the orifice shrunk by approximately $50 \%$ over the first year and then remained relatively stable (personal communication). Referral centres occasionally see patients with symptomatic papillary stenosis following a timid sphincterotomy but we believe that in the last decade this has become an increasingly rare occurrence.

The authors examined a total of 15 risk factors and ultimately identified five that were significant in univariate analysis. These were then entered into a multivariate model which demonstrated three significant risk factors for stone recurrence. Rather than a hypothesis driven approach based on prior published studies, the authors chose to use a more exploratory approach. In the end, their findings were consistent with previous studies. They demonstrated three risk factors for recurrent choledocholithiasis after EBS, two of which (bile duct diameter $>15 \mathrm{~mm}$ and periampullary diverticulum) had been described previously. ${ }^{10}$ A new risk factor identified by this study was interval between initial EBS and repeat ERCP $<5$ years.

The authors state that none of the patients with bile duct diameters $>15 \mathrm{~mm}$ had choledochal cysts. One has to ask: how did they know? It can be very difficult to distinguish a dilated bile duct from congenital dilatation of the extrahepatic biliary tree (type I choledochal cyst). ${ }^{11}$ Choledochal cysts typically exhibit poor drainage, even after EBS, and are a "hot bed" for recurrent choledocholithiasis and cholangitis. The authors talk about periampullary diverticula causing "compression" of the distal bile duct. This is at odds with the current consensus that periampullary diverticula promote stone formation by a combination of bacterial overgrowth (with ascending infection) and motility disturbance (sphincter of Oddi dysfunction). This study is limited by its retrospective nature and the heterogeneity of the patient population. One wonders how many sphincterotomies are "enough"? Urban legend (but no hard data) holds that extending a prior sphincterotomy risks perforation. It seems that repeat EBS does the job (allowing access to remove stones, improving biliary drainage) although in the present study three patients had early recurrence of biliary symptoms after their second EBS.

What about balloon sphincteroplasty as an alternative to repeat EBS?
Unfortunately, it appears that dilating the papilla rather than cutting it does not reduce the incidence of recurrent stones. ${ }^{12}$ The overall complication rates of EBS and balloon sphincteroplasty are approximately equal but the balloon technique carries an increased risk of post-procedure pancreatitis. ${ }^{13}$ That being the case, most ERCP endoscopists reserve balloon dilation of the papilla for special circumstances, such as coagulopathy that renders EBS dangerous. It would be interesting to know if balloon sphincteroplasty is equivalent to EBS in efficacy for managing recurrent choledocholithiasis after sphincterotomy.

Despite its limitations, the study of Sugiyama and colleagues ${ }^{7}$ suggests that late complications of EBS are more common than we imagine. The good news is that repeat EBS manages almost all of these episodes of late cholangitis and recurrent choledocholithiasis effectively. Patients who recurrently develop biliary sludge and stones despite EBS most likely have difficulty emptying a dilated bile duct. Sometimes the best results are obtained by surgery. Typically, a biliary bypass of some variety (for example, choledochoduodenostomy, choledochojejunostomy) will be performed at the end of open bile duct exploration and stone clearance. The presence of a choledochal cyst usually requires resection of the affected segment with a high Roux-type biliary diversion. Elderly patients often sail through anaesthesia and biliary surgery without turning a hair, and should be evaluated by an experienced biliary surgery before being labelled as "unsuitable for surgery/anaesthesia". That EBS predisposes to bile duct cancer (cholangiocarcinoma) is another urban legend that this study effectively debunks: none was seen in this study population. Endoscopists since 1974 have been convinced of the old surgical maxim that "a chance to cut is a chance to cure". We believe that this study supports that belief, with the caveat that recurrent choledocholithiasis and its complications may be more common than we care to believe.

Gut 2004;53:1725-1727. doi: $10.1136 /$ gut.2004.046185

\section{Authors' affiliations}

S Sultan, J Baillie, Duke University Medical Center, Durham, NC, USA

Correspondence to: Dr J Baillie, Duke University Medical Center, Rm 0339 Orange Zone, South Hospital, Trent Drive, Durham, NC 27710, USA; baillo01@mc.duke.edu 


\section{REFERENCES}

1 Classen M, Demling L. Endoscopic sphincterotomy of the papilla of Vater and extraction of stones from the choledochal duct. (in German). Dtsch Med Wochenschr 1974:99:496-7.

2 Kawai K, Akasaka Y, Murakami K, et al. Endoscopic sphincterotomy of the ampulla of Vater. Gastrointest Endosc 1974;20: 148-51.

3 National Institute of Health State-of the-Science Conference Statement. Endoscopic retrograde cholangiopancreatography for diagnosis and therapy. Bethesda: $\mathrm{NIH}, 2002$.

4 Bergmann JJ, Van der Mey S, Raves EA, et al. Long-term follow-up after endoscopic sphincterotomy for bile duct stones in patients younger than 60 years of age. Gastrointest Endosc 1996;44:643-9.
5 Freeman ML, Nelson DB, Sherman S, et al. Complications of endoscopic biliary sphincterotomy. N Engl J Med 1996;335:909-19

6 Prat F, Malak NA, Pelletier G. Biliary symptoms and complications more than 8 years after endoscopic sphincterotomy for choledocholithiasis. Gastroenterology 1996;110:894-9.

7 Sugiyama M, Suzuki Y, Abe N, et al. Endoscopic retreatemnet of recurrent choledocholithiasis after sphincterotomy. Gut 2004;53:1856-9.

8 Sugiyama M, Atomi Y. Follow-up of more than 10 years after endoscopic sphincterotomy for choledocholithiasis in young patients. Br J Surg 1998:85:917-21.

9 Periera-Lima JC, Jakobs, R, Winter U, et al. Longterm results (7-10 years) of endoscopic papillotomy for choledocholothiasis. Multivariate analysis of prognostic factors for the recurrence of biliary symptoms. Gastrointest Endosc 1998:48:457-64.

10 Kim D, Kim M-H, Lee SK, et al. Risk factors for recurrence of primary bile duct stones after endoscopic biliary sphincterotomy. Gastrointest Endosc 2001:54:42-8.

11 Todani T, Watanabe $Y$, Narusue $M$, et al. Congenital bile duct cysts: classification, operative procedures, and review of 37 cases, including cancer arising from choledochal cyst. Am J Surg 1977;134:263-9.

12 Ueno N, Ozawa Y. Endoscopic sphincter dilation in patients with bile duct stones: intermediate and medium-term results. J Gastroenterol Hepatol 1999; 14:822-6.

13 Huibregtse K. Endoscopic balloon dilation for removal of bile duct stones: special indications only. Endoscopy 2001;33:620-2.

\section{Molecular diagnosis of pancreatobiliary malignancies in brush cytologies of biliary strictures}

\section{T M Gress}

\section{Do molecular techniques improve the diagnostic accuracy of brush cytologies of biliary strictures?}

A ccurate diagnosis of strictures involving the bile duct is essential to the planning of therapy and the choice of the right treatment option, such as surgical resection or endoscopic stenting. However, differentiation of malignant from benign ductal lesions at endoscopic retrograde cholangiopancreatography (ERCP) remains a challenge. Although cholangiographic features may be characteristic for malignant or benign disease, in many cases histological or cytological proof of the diagnosis is required to determine the optimal treatment for each individual patient. Histological and cytological tissue diagnoses may be obtained by several methods, including open biopsy, ultrasound or computed tomography guided fine needle aspiration or core biopsy, endoscopic forceps biopsy, endoscopic brush cytology, and bile aspiration cytology. ${ }^{1-4}$

Brush cytology performed at ERCP has become the preferred initial method of pursuing tissue diagnosis in many patients with pancreatobiliary strictures. ${ }^{5-9}$ The technique allows easy and convenient sampling and has a low complication rate. ${ }^{310}$ The diagnostic specificity of biliary brush cytology is very high and few false positive diagnoses have been reported. The major limitation of the technique has been the relatively modest diagnostic sensitivity. The sensitivity rates reported in multiple studies are highly variable and range between $30 \%$ and $88 \%$, with nearly $100 \%$ specificity. ${ }^{34-12}$ In general, results of brush cytology for biliary strictures induced by pancreatic malignancies have proved to be inferior (on average $46 \%$ ) to those observed for biliary malignancies (on average 68\%). ${ }^{4}$

The success rate of brush cytology analyses is largely dependent on two factors: (1) the quality of the cytological material obtained at ERCP and (2) the expertise of the cytopathologist.

The quality of the cytological material is influenced by the processing technique, cellularity, cellular preservation, background, quantity of diagnostic cells, and cells not characteristic for biliary lesions such as duodenal mucosa. ${ }^{9}$ Many of these parameters are difficult to control and may require repeated brushings, alternative sampling approaches such as forceps biopsies, ${ }^{13}{ }^{14}$ or changes in sample processing techniques. The fraction of brush cytologies that were non-diagnostic due to reduced quality of the cytological sample has generally been described to be as low as $5 \% .^{10-12}$ The study by Wight and colleagues ${ }^{15}$ highlights the paramount importance of the expertise of the cytopathologist. In this study, a review of 137 consecutive biliary brushings from 127 patients by two expert cytopathologists improved the sensitivity from $49.4 \%$ to $89 \%$. Some of these problems arise from inconsistencies in the criteria used for classification of cells on cytological slides. While morphological criteria for benign and reactive changes of duct epithelial cells and for adenocarcinoma cells are well established and utilised in many studies, ${ }^{9}$ problems and inconsistencies mainly arise in the categorisation of lesions not fulfilling all criteria of malignancy. Classification of such cells has been termed to be a "cytological grey zone" by Selvaggi ${ }^{9}$ and includes categories such as atypical, dysplasia (low and high grade), and suspicious. The morphological criteria used for this classification show significant overlap in various studies, ${ }^{9}$ and some authors even include suspicious or atypical lesions in the calculation of sensitivity. ${ }^{15-17}$ Thus comparison of the sensitivity and specificity rates obtained in various studies are hampered by the inconsistencies in the definition of cytological criteria in this "cytological grey zone".

In this unsatisfactory situation, ancillary diagnostic modalities have been increasingly tested to improve the yield of brush cytologies. These include flow cytometry for DNA analysis of aneuploidy, ${ }^{18} 19$ morphometry for assessing nuclear area, nuclear DNA content, chromatin distribution, ${ }^{20} 21$ telomerase RNA, $^{22}$ as well as CA-19-9 and CEA measurements ${ }^{19}$ in bile fluid. Many of these studies have shown some promising results but are either not widely available or provide only a limited advantage over cytology alone and have thus not led to a significant improvement.

The use of molecular techniques as adjunct to biliary brushing cytology has so far focused on the detection of K-ras codon 12 and p53 alterations. 
Immunohistochemistry analyses for p53 protein have yielded contradictory results ${ }^{23-25}$ and are presently not used in the diagnostic routine. Analyses of K-ras codon 12 mutations in brush cytologies have also yielded unsatisfactory results. It has been shown that K-ras mutations are more frequently found in strictures induced by pancreatic cancers and are not, or less frequently, found in strictures induced by bile duct cancers. Van Laethem et al found a sensitivity for biliary disease of $24 \%$ in bile duct and pancreatic duct brushings compared with $81 \%$ for pancreatic diseases. ${ }^{26}$ In the same study, however, K-ras mutations were found in $25 \%$ of patients with chronic pancreatitis, without evidence of malignancy even after a short period of follow up, thus reducing the specificity to $72 \%$ compared with $100 \%$ for cytology. This finding is supported by other studies reporting the presence of $\mathrm{K}$-ras codon 12 mutations in chronic pancreatitis and in normal pancreas ${ }^{27-29}$ without evidence of pancreatic cancer development during follow up. Thus at least for strictures induced by pancreatic diseases, analysis of K-ras mutations is of no additional value as their presence will not provide unequivocal proof for the malignant nature of the stricture. For biliary tract cancers the rates of $\mathrm{K}$-ras mutations reported in the literature vary widely, ranging between $0 \%$ and $100 \%,{ }^{30}$ and the value of $\mathrm{K}$-ras mutation detection in brush cytologies of biliary strictures appears even more conflicting. The location of the biliary tumour (proximal or distal bile duct, intrahepatic bile ducts, gall bladder), racial and geographic variation, as well as the methods used for mutation detection have been assumed to cause these differences in the incidence of K-ras codon 12 mutations. Furthermore, individual reports indicate that at least in patients with primary sclerosing cholangitis, K-ras mutations may as well be detected without evidence of carcinoma, ${ }^{31}$ which limits the use of $\mathrm{K}$-ras mutation detection in patients with biliary strictures.

In the context of this unsatisfactory situation, the study of Khalid and colleagues $^{32}$ reported in this issue of Gut presents a novel approach for molecular analyses of brush cytologies of biliary strictures obtained during ERCP (see page 1860). As molecular indicators of malignancy, the authors used tumour suppressor gene linked microsatellite marker loss of heterozygosity (LOH) and K-ras codon 12 mutations. An interesting sampling procedure was used employing manual microdissection of normal and abnormal appearing cells on alcohol fixed Papanicolau stained cytology slides.
DNA from two different sampling strategies was used in their study. One was termed "collective assembly" (CA) and involved the combination of separate aggregates of abnormal appearing cell clusters of one brush cytology sample to obtain a sufficient number of cells (approximately 1000) allowing direct molecular analyses. As this strategy was assumed to produce an averaging of mutational changes among the aggregated microdissected cells due to intratumoral heterogeneity of genetic alterations, a second approach was adopted. This approach involved the use of a whole genome amplification technique (WGA) of discrete clusters of 50-100 cells, which in theory should represent individual cytological lesions. However, the anticipated drawback of this technique is the introduction of artefacts and a bias due to the amplification step. As a normal control, the authors used either surgically resected non-neoplastic tissue from the same patient, where available, or normal appearing cellular material from the same brush cytology. To verify the validity of the results, the same molecular analyses were done with microdissected material obtained from surgically resected specimens from the same patients where available.

The most impressive result was that the molecular analyses of polymerase chain reaction amplified DNA from microdissected brush cytology cell clusters discriminated reactive from malignant cells with $100 \%$ sensitivity, specificity, and accuracy. Minor variations in chromosomal imbalances between the studied cytological samples and the corresponding surgically resected tissue were attributed to intratumoral mutational heterogeneity. Although the study is intriguing and delivers evidence for the potential value of molecular diagnostic tools for the differential diagnosis of gastrointestinal tumours such as pancreatobiliary malignancies, some issues must be kept in mind when assessing the data. Naturally, a study of 26 patients with mixed types of tumours and controls (six pancreatic cancers, 11 cholangiocarcinomas and nine not further defined benign biliary strictures) will always be preliminary and should be confirmed prospectively in a larger series of patient samples obtained in a blinded manner. The approach is based on the detection of abnormal looking cells on cytological slides. The authors define "abnormal looking cells" in inconclusive cases as cells fulfilling most, but not all, of the criteria for malignancy such as nuclear enlargement, pleomorphism, elevated $\mathrm{N} / \mathrm{C}$ ratio, nuclear membrane integrity, and coarse chromatin. This classification varies from the categories used by many other cytologists which usually comprise categories such as suspicious, atypical, or dysplastic," reflecting the lack of standardisation of morphological criteria used to classify cells in this "cytological grey zone". As in all cases a sufficient number of cells could be microdissected, there were obviously no non-diagnostic cases in the present study. Ten brush cytologies from biliary strictures were inconclusive in the cytological evaluation; only one was derived from a benign stricture. Eight of nine brush cytologies from benign strictures were negative for malignant or abnormal appearing cells. Thus the presence of abnormal looking cells in cytology alone was sufficient for the diagnosis of malignancy in 9/10 cases with inconclusive cytology and the presented molecular approach helped to exclude malignancy in one case. As mentioned above, some cytologists have used the presence of suspicious or atypical cells in brush cytologies for a classification of positive for malignancy. ${ }^{15-17}$ In the absence of clear definitions and criteria for the classification of these types of cells, this interpretation appears controversial. The molecular approach presented in the study by Khalid and colleagues $^{32}$ provides a powerful tool for standardisation of the morphological criteria used to categorise lesions in this "cytological grey zone". It offers the possibility of identifying and describing cells that are found to be malignant in the molecular approach thus allowing an increase in the sensitivity of the cytological evaluation.

Unfortunately, this molecular approach offers no solution for nondiagnostic brush cytology samples as it requires identification of abnormal and normal cells. In this situation a technique not requiring identification of intact "abnormal looking" cells (for example, by using suspensions obtained from brush cytologies) would clearly be of great value.

A further interesting finding in the study by Khalid and colleagues ${ }^{32}$ is the observation that all cholangiocarcinomas in their series did not show K-rascodon 12 mutations in contrast with the majority of pancreatic cancers. As mentioned above, data on the presence of K-ras mutations in biliary tract cancers are controversial and mutation rates reported in the literature show a high degree of variation. ${ }^{30}$ Most studies however report that the frequency of K-ras mutations in biliary tract cancers is lower than in pancreatic ductal adenocarcinomas. Nevertheless, it appears that we cannot assume that K-ras mutations are absent in biliary tract cancers, and it even appears that mutations may arise 
in inflammatory disorders such as primary sclerosing cholangitis. ${ }^{31}$ Most likely the observation described in the current study is due to the low number of patients and we may expect to find a low but significant proportion of biliary tract cancers with K-ras mutations with an increasing number of patients. Thus the presence of a K-ras mutation in the brush cytology of a biliary stricture should not lead us to assume that the malignancy must be of pancreatic origin. What is more, as discussed above, the presence of K-ras mutations does not even indicate the presence of malignancy at all, as many patients with chronic pancreatitis show K-ras mutations.

To summarise, the study by Khalid and colleagues ${ }^{32}$ represents a significant advance as the presented $\mathrm{LOH}$ approach using microdissected cells provides a tool to verify the nature of cells in the "cytological grey zone" of brush cytologies of biliary strictures usually classified as suspicious, atypical, or dysplastic using different morphological criteria. It may thus help to standardise the criteria to define cells in the "cytological grey zone" and may allow an increase in the sensitivity of brush cytology by clearly identifying cells indicative of malignancy. So far this can only be done by follow up studies of patients or by histological analysis of surgically resected tumours.

Gut 2004;53:1727-1729.

doi: 10.1136/gut.2004.046177

Correspondence to: Professor T M Gress, Department of Internal Medicine I, University Hospital of Ulm, Robert Koch Str 8, 89081 Ulm, Germany; thomas.gress@medizin.uni-ulm.de

\section{REFERENCES}

1 Fogel EL, Sherman S. How to improve the accuracy of diagnosis of malignant biliary strictures. Endoscopy 1999;31:758-60.

2 Ponchon T. Diagnostic endoscopic retrograde cholangiopancreatography. Endoscopy 2000;32:200-8.
3 Farrell RJ, Jain AK, Brandwein SL, et al. The combination of stricture dilation, endoscopic needle aspiration, and biliary brushings significantly improves diagnostic yield from malignant bile duct strictures. Gastrointest Endosc 2001;54:587-94

4 Glasbrenner B, Ardan M, Boeck W, et al. Prospective evaluation of brush cytology of biliary strictures during endoscopic retrograde cholangiopancreatography. Endoscopy 1999:31:712-17.

5 Foutch PG, Kerr DM, Harlan JR, et al. A prospective, controlled analysis of endoscopic cytotechniques for diagnosis of malignant biliary strictures. Am J Gastroenterol 1991;86:577-80.

6 Kurzawinski TR, Deery A, Dooley JS, et al. A prospective study of biliary cytology in 100 patients with bile duct strictures. Hepatology 1993:18:1399-403.

7 Kurzawinski T, Deery A, Dooley J, et al. A prospective controlled study comparing brush and bile exfoliative cytology for diagnosing bile duct strictures. Gut 1992;33:1675-7.

8 Mansfield JC, Griffin SM, Wadehra V, et al. A prospective evaluation of cytology from biliary strictures. Gut 1997;40:671-7.

9 Selvaggi SM. Biliary brushing cytology. Cytopathology 2004;15:74-9.

10 Govil H, Reddy V, Kluskens L, et al. Brush cytology of the biliary tract: retrospective study of 278 cases with histopathologic correlation. Diagn Cytopathol 2002;26:273-7.

11 Stewart CJ, Mills PR, Carter R, et al. Brush cytology in the assessment of pancreatico-biliary strictures: a review of 406 cases. J Clin Pathol 2001;54:449-55

12 Vandervoort J, Soetikno RM, Montes $\mathrm{H}$, et al. Accuracy and complication rate of brush cytology from bile duct versus pancreatic duct. Gastrointest Endosc 1999;49:322-7.

13 Pugliese V, Conio M, Nicolo G, et al. Endoscopic retrograde forceps biopsy and brush cytology of biliary strictures: a prospective study. Gastrointest Endosc 1995;42:520-6.

14 Schoefl R, Haefner M, Wrba F, et al. Forceps biopsy and brush cytology during endoscopic retrograde cholangiopancreatography for the diagnosis of biliary stenoses. Scand J Gastroenterol 1997;32:363-8.

15 Wight CO, Zaitoun AM, Boulton-Jones JR, et al. Improving diagnostic yield of biliary brushings cytology for pancreatic cancer and cholangiocarcinoma. Cytopathology 2004; 15:87-92.

16 Layfield U, Wax TD, Lee JG, et al. Accuracy and morphologic aspects of pancreatic and biliary duct brushings. Acta Cytol 1995;39:1 1-18.

17 Lee JG, Leung JW, Cotton PB, et al. Diagnostic utility of K-ras mutational analysis on bile obtained by endoscopic retrograde cholangiopancreatography. Gastrointest Endosc 1995;42:317-20.

18 Ryan ME, Baldauf MC. Comparison of flow cytometry for DNA content and brush cytology for detection of malignancy in pancreaticobiliary strictures. Gastrointest Endosc 1994;40:133-9.
19 Lindberg B, Arnelo U, Bergquist A, et al. Diagnosis of biliary strictures in conjunction with endoscopic retrograde

cholangiopancreaticography, with special reference to patients with primary sclerosing cholangitis. Endoscopy 2002;34:909-16.

20 Sears RJ, Duckworth CW, Decaestecker C, et al Image cytometry as a discriminatory tool for cytologic specimens obtained by endoscopic retrograde cholangiopancreatography. Cancer 1998;84:119-26.

21 Krishnamurthy S, Katz RL, Shumate A, et al. DNA image analysis combined with routine cytology improves diagnostic sensitivity of common bile duct brushing. Cancer 2001;93:229-35.

22 Morales CP, Burdick JS, Saboorian MH, et al. In situ hybridization for telomerase RNA in routine cytologic brushings for the diagnosis of pancreaticobiliary malignancies. Gastrointest Endosc 1998;48:402-5.

23 Lee CS, Pirdas A. p53 protein immunoreactivity in cancers of the gallbladder, extrahepatic bile ducts and ampulla of Vater. Pathology 1995;27:117-20.

24 Sturm PD, Hruban RH, Ramsoekh TB, et al. The potential diagnostic use of K-ras codon 12 and p53 alterations in brush cytology from the pancreatic head region. $J$ Pathol pancreatic head regio

25 Stewart CJ, Burke GM. Value of p53 immunostaining in pancreatico-biliary brush cytology specimens. Diagn Cytopathol 2000;23:308-13.

26 Van Laethem JL, Bourgeois V, Parma J, et al. Relative contribution of $\mathrm{Ki}$-ras gene analysis and brush cytology during ERCP for the diagnosis of biliary and pancreatic diseases. Gastrointest Endosc 1998;47:479-85.

27 Yanagisawa A, Ohtake K, Ohashi K, et al. Frequent $\mathrm{c}-\mathrm{Ki}$-ras oncogene activation in mucous cell hyperplasias of pancreas suffering from chronic inflammation. Cancer Res 1993;53:953-6.

28 Tada M, Ohashi M, Shiratori Y, et al. Analysis of K-ras gene mutation in hyperplastic duct cells of the pancreas without pancreatic disease. Gastroenterology 1996;1 10:227-31

29 Pugliese V, Pujic N, Saccomanno S, et al. Pancreatic intraductal sampling during ERCP in patients with chronic pancreatitis and pancreatic cancer: cytologic studies and k-ras-2 codon 12 molecular analysis in 47 cases. Gastrointest Endosc 2001;54:595-9.

30 Rashid A. Cellular and molecular biology of biliary tract cancers. Surg Oncol Clin N Am 2002;11:995-1009.

31 Kubicka S, Kuhnel F, Flemming $P$, et al. K-ras mutations in the bile of patients with primary sclerosing cholangitis. Gut 2001;48:403-8.

32 Khalid A, Pal R, Sasatomi E, et al. Use of microsatellite marker loss of heterozygosity in accurate diagnosis of pancreatobiliary malignancy from brush cytology samples. Gut 2004:53:1860-5. 